\title{
Impaired activity of protease inhibitors towards neutrophil elastase bound to human articular cartilage
}

\author{
Kazuhito Kawabata, Adrian R Moore, Derek A Willoughby
}

\begin{abstract}
Objective-To investigate the effects of protease inhibitors on the ability of free and cartilage bound neutrophil elastase to degrade cartilage proteoglycan in vitro.

Methods-Cryostat sections of human articular cartilage were used as substrate, and proteoglycan loss induced by free or cartilage bound elastase was quantified by alcian blue staining, followed by scanning and integrating microdensitometry.

Results-High molecular mass protease inhibitors ( $\alpha_{1}$ protease inhibitor, $\alpha_{2}$ macroglobulin, and soya bean trypsin inhibitor) and synovial fluid from patients with rheumatoid arthritis were effective in blocking proteoglycan loss from sections treated with free elastase, but their activity towards cartilage bound elastase was much reduced. In contrast, low molecular mass elastase inhibitors ( $\mathbf{N}$-methoxysuccinyl-AlaAla-Pro-Val chloromethyl ketone and ONO5046 (N-[2-[4-(2,2-dimethylpropionyloxy) phenylsulphonylamino]benzoyl] aminoacetic acid) were effective against free and cartilage bound elastase.

Conclusion-The binding of elastase to cartilage appears to be a mechanism whereby the enzyme can remain active in the presence of high molecular mass protease inhibitors.
\end{abstract}

(Ann Rheum Dis 1996; 55: 248-252)

The infiltration of mononuclear cells and neutrophils into the synovial tissue is a characteristic of rheumatoid arthritis (RA). These cells, through elaboration of reactive oxygen species ${ }^{1}$ and lysosomal enzymes, ${ }^{2}$ have been implicated in the pathological degradation of cartilage in RA. The serine protease, neutrophil elastase, may have particular significance. This enzyme is contained in neutrophils and mononuculear cells ${ }^{3}$ and is capable of degrading a variety of tissue components, including the major cartilage components: type II collagen and proteoglycan. ${ }^{2}$ Elastase has also been shown to be the main mechanism whereby neutrophils degrade cartilage matrix in vitro. ${ }^{4}$

The activity of free elastase is regulated by protease inhibitors, such as $\alpha_{1}$ protease inhibitor $\left(\alpha_{1}\right.$ PI) and $\alpha_{2}$ macroglobulin $\left(\alpha_{2} M G\right)$ in body fluids. However, recent work has shown that elastase damages cartilage even in the presence of these inhibitors. ${ }^{5}$ Several mech- anisms have been proposed by which a local imbalance between elastase and protease inhibitors might occur, including the exclusion of $\alpha_{1}$ PI. from the neutrophil/cartilage microenvironment and inactivation of $\alpha_{1}$ PI and $\alpha_{2}$ MG by neutrophil derived reactive oxygen species and proteases. ${ }^{6}$

Neutrophil elastase has a high affinity for cartilage $^{7}$ and localises on articular cartilage of patients with RA. ${ }^{8}$ The finding that elastase bound to elastin is resistant to protease inhibition ${ }^{9}{ }^{10}$ raised the possibility that elastase bound to cartilage might behave similarly and provide yet another mechanism whereby elastase could remain active in inflamed joints. In the current study, we examined the inhibitory activity of several protease inhibitors on cartilage proteoglycan degradation induced by free and cartilage bound elastase. The inhibitors studied were of two distinct classes: high molecular mass protease inhibitors $\left(\alpha_{2} \mathrm{MG}\right.$ (725 kDa), $\alpha_{1}$ PI ( $\left.52 \mathrm{kDa}\right)$, and soya bean trypsin inhibitor (SBTI) (20 kDa)) and synthetic low molecular mass protease inhibitors (N-methoxysuccinyl-Ala-Ala-Pro-Val-chloromethylketone (CMK) $(0.5 \mathrm{kDa})^{11}$ and ONO5046 (N- [2-[4-(2,2-dimethylpropionyloxy) phenylsulphonylamino]benzoyl] aminoacetic acid $(0.5 \mathrm{kDa}) .{ }^{12}$

\section{Methods}

CHEMICALS

We obtained $\alpha_{1}$ PI, $\alpha_{2}$ MG, SBTI, and human neutrophil elastase (chromatographically purified, $3.3 \mathrm{U} / \mathrm{mg}$ protein with $\mathrm{N}$-methoxysuccinyl Ala-Ala-Pro-Val p-nitroanilide as a substrate at $25^{\circ} \mathrm{C}$ ) from Calbiochem (Novabiochem (UK) Ltd, Nottingham, UK). CMK was from Sigma Chemical Co Ltd (Dorset, UK), and ONO-5046 from ONO Pharmaceutical Co Ltd (Osaka, Japan). Neutrophil elastase and protease inhibitors (except ONO-5046) were dissolved in Tris- $\mathrm{HCl}$ buffer $(0.2 \mathrm{~mol} / 1, \mathrm{pH}$ $8 \cdot 0$, containing $10 \mathrm{mmol} / \mathrm{l}$ of calcium chloride). ONO-5046 was initially dissolved in dimethyl sulphoxide (DMSO) and then diluted with Tris- $\mathrm{HCl}$ buffer to achieve a final concentration of DMSO less than $0 \cdot 1 \%$; this concentration of DMSO was found to have no effect on the subsequent assays.

\section{SYNOVIAL FLUIDS}

Synovial fluids were obtained from the knee joints of six patients with RA fulfilling the 
American Rheumatism Association 1987 diagnostic criteria ${ }^{13}$ and having clinical indication for joint aspiration, and were collected into $10 \mathrm{mmol} / 1$ EDTA. Cells were removed by centrifugation and the supernatants stored at $-80^{\circ} \mathrm{C}$. Before use, the synovial fluids were pooled and the pooled sample shown to be devoid of neutrophil elastase activity using N-methoxysuccinyl Ala-Ala-Pro-Val p-nitroanilide as substrate. ${ }^{14}$

\section{CARTILAGE}

Human cartilage samples were obtained from adults within six hours after death and were removed from macroscopically normal areas of the non-weight-bearing posterior surface of the femoral condyle. Blocks of $3 \mathrm{~mm}^{3}$ were cut, snap frozen by precipitate immersion in $\mathrm{n}$-hexane at $-80^{\circ} \mathrm{C}$ and stored in liquid nitrogen until required for use. Full depth sections of cartilage were cut at $4 \mu \mathrm{m}$ on a cryostat and mounted onto 12 spot teflon coated slides that had previously been treated with $10 \%$ poly-L-lysine as a section adhesive.

\section{EFFECTS OF PROTEASE INHIBITORS ON FREE} NEUTROPHIL ELASTASE

Cartilage sections were incubated at $37^{\circ} \mathrm{C}$ for two hours with $30 \mu \mathrm{l}$ of buffer, neutrophil elastase $0.031-0.31 \mu \mathrm{mol} / \mathrm{l}$, or neutrophil elastase $0.31 \mu \mathrm{mol} / 1$ in combination with various concentrations of protease inhibitors or synovial fluid.

EFFECTS OF PROTEASE INHIBITORS ON CARTILAGE BOUND NEUTROPHIL ELASTASE Neutrophil elastase was absorbed onto cartilage sections by incubation with neutrophil elastase $0.31 \mu \mathrm{mol} / 1$ at $0^{\circ} \mathrm{C}$ for 15 minutes, followed by extensive washings with $\mathrm{Tris}-\mathrm{HCl}$ buffer at $1^{\circ} \mathrm{C}$. Sections were treated with buffer, various concentrations of protease inhibitors, or synovial fluid at $1^{\circ} \mathrm{C}$ before being incubated at $37^{\circ} \mathrm{C}$ for two hours.
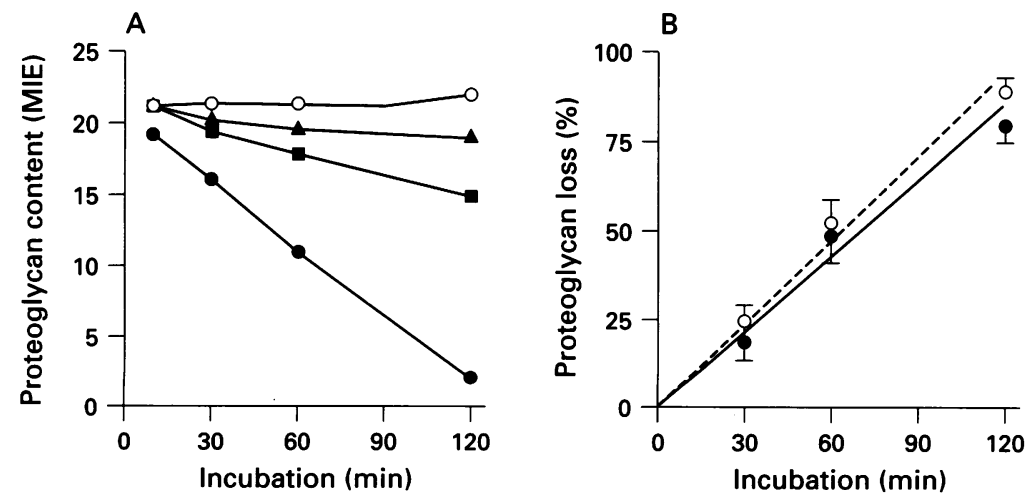

Figure 1 A: Kinetics of cartilage proteoglycan degradation by free neutrophil elastase. Cartilage sections incubated with $0.031 \mu \mathrm{mol} /(\Delta), 0.1 \mu \mathrm{mol} /(\square)$, or $0.31 \mu \mathrm{mol} /\left(\mathbf{O}^{\prime}\right)$ of the free enzyme, or with buffer (O). Cartilage proteoglycan content (assessed by alcian blue staining and microdensitometry) expressed as mean integrated extinction (MIE). Each point represents the mean of two experiments. B: Comparison of the kinetics of cartilage proteoglycan degradation induced by free $(\mathrm{O})$ and cartilage bound $(\mathrm{O})$ neutrophil elastase $0.31 \mu \mathrm{mol}$. Data expressed as percentage proteoglycan degradation compared with buffer treated control sections. Each point represents the mean (SD) of three experiments.
ASSESSMENT OF CARTILAGE PROTEOGLYCAN LOSS

After incubation, cartilage sections were washed, fixed with $0.9 \%$ sodium chloride supplemented with $4 \% \mathrm{w} / \mathrm{v}$ formaldehyde and sulphated glycosaminoglycans, and stained overnight with alcian blue $(8 \mathrm{GX}, 0.05 \%$ in $0.025 \mathrm{~mol} / \mathrm{l}$ acetate buffer containing $0.5 \mathrm{~mol} / 1$ magnesium chloride) before being dehydrated, cleared, and mounted. Dye content of the cartilage sections was quantified as described previously, ${ }^{4}$ with a Vickers M85 scanning and integrating microdensitometer using a $\times 40$ objective, a wavelength of $550 \mathrm{~nm}$, a band width of $20 \mathrm{~nm}$, a mask diameter of $15 \mu \mathrm{m}$, and scanning spot size of $0.2 \mu \mathrm{m}$. For each section, clear field readings (background) and clear field readings with an imposed neutral density of 1.0 (ND1) were taken. Six integrated readings were taken from areas of hyaline cartilage beneath the articular surface and from areas of matrix free of lacunae. From these values, the mean integrated extinction (MIE) was calculated as (mean integrated absorbance-background)/ND1.

\section{DATA ANALYSIS}

Activity of protease inhibitors or synovial fluid towards free or cartilage bound neutrophil elastase was calculated as percentage inhibition in relation to sections treated with enzyme alone and sections treated with buffer. Results were expressed as mean (SD). The differences between groups were assessed on untransformed data using unpaired Student's $t$ test, with $\mathrm{p}<0.05$ taken to indicate a significant difference.

\section{Results}

KINETICS OF PROTEOGLYCAN DEGRADATION BY FREE NEUTROPHIL ELASTASE

The degradation of cartilage proteoglycan by free neutrophil elastase $0.031-0.31 \mu \mathrm{mol} / 1$ was linear over two hours (fig 1A). When the data at two hours were expressed in terms of proteoglycan degradation versus enzyme concentration, the relationship was again linear $(r=0.999)$.

\section{PREPARATION OF CARTILAGE BOUND}

NEUTROPHIL ELASTASE

When cartilage sections were treated with neutrophil elastase $0.31 \mu \mathrm{mol} / \mathrm{l}$ for up to 15 minutes at $0^{\circ} \mathrm{C}$, no proteoglycan degradation was seen (data not shown). However, if these treatments were followed by extensive washings and then a secondary two hour incubation with Tris- $\mathrm{HCl}$ buffer at $37^{\circ} \mathrm{C}$, marked proteoglycan loss was observed that was dependent on the initial incubation time with neutrophil elastase: 30.4 (SD 11.0)\%, $52.3(6.0) \%, 80.0$ $(14 \cdot 1) \%, 82 \cdot 5(12 \cdot 3) \%$, and $93.5(10.9) \%$ loss at 0.5 , one, two, five, and 15 minutes of neutrophil elastase treatment, respectively. Fifteen minutes incubation with neutrophil elastase was therefore chosen as optimal for the binding of enzyme to cartilage. Dissociation of 

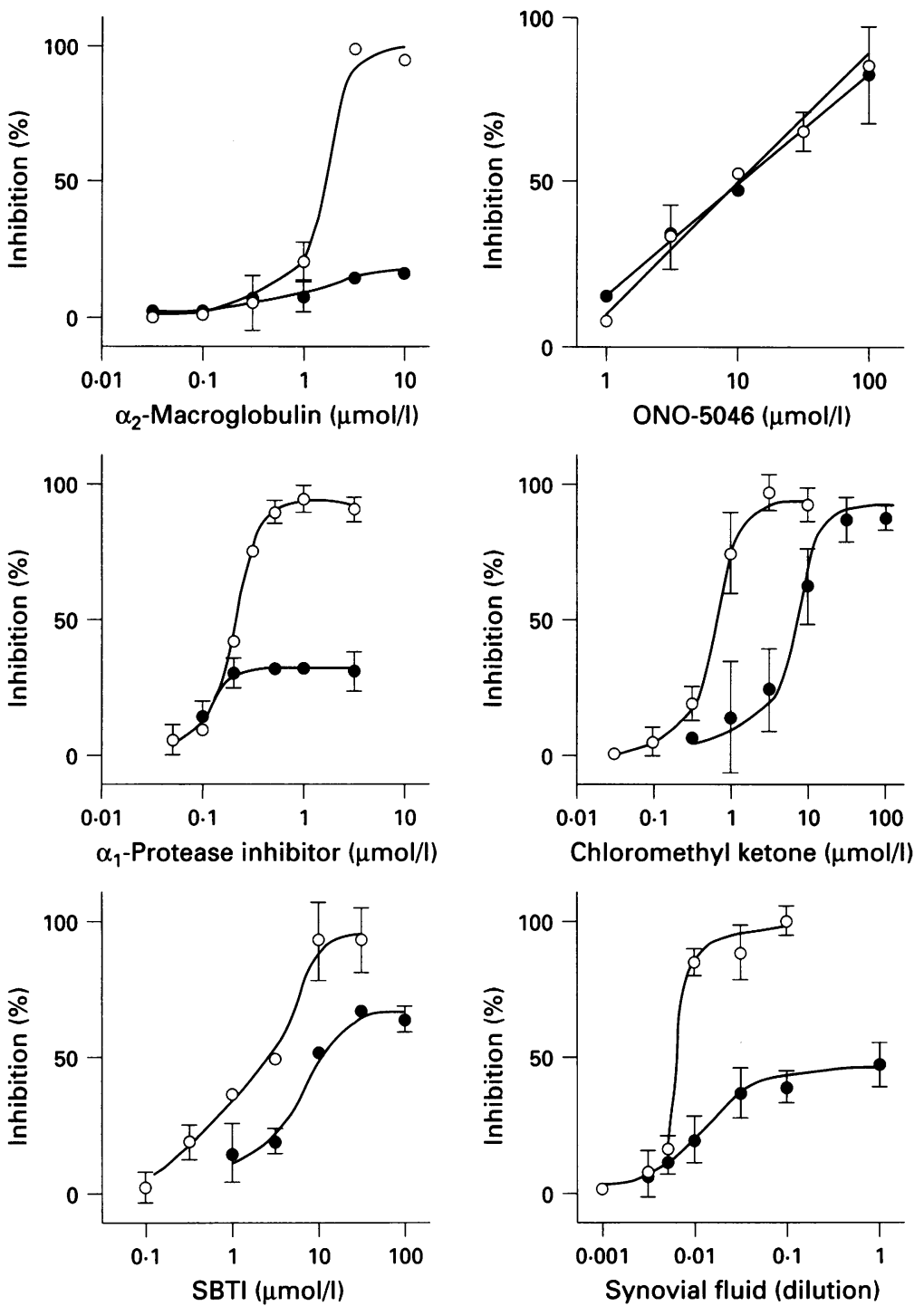

Figure 2 Effects of protease inhibitors and synovial fluid on the ability of free ( $O)$ and cartilage bound (O) neutrophil elastase to degrade cartilage proteoglycan. Cartilage proteoglycan content was assessed by alcian blue staining and microdensitometry, and percentage inhibition determined in comparison with buffer (100\% inhibition) and enzyme treated sections (0\% inhibition). Each point represents the mean (SD) of four experiments.

neutrophil elastase from the cartilage during the second two hour incubation was less than $1 \%$ of initially bound material as judged by the neutrophil elastase activity recovered from the incubation buffer (data not shown).

KINETICS OF PROTEOGLYCAN DEGRADATION BY CARTILAGE BOUND NEUTROPHIL ELASTASE The degradation of cartilage proteoglycan by cartilage bound neutrophil elastase was linear over two hours and showed kinetics identical to those of the degradation induced by free enzyme (fig 1B).

ACTIVITIES OF PROTEASE INHIBITORS AND SYNOVIAL FLUID ON FREE AND CARTILAGE BOUND NEUTROPHIL ELASTASE

Figure 2 shows the data on high molecular mass inhibitors ( $\alpha_{2} M G, \alpha_{1}$ PI, and SBTI), low molecular mass inhibitors (CMK and ONO5046), and synovial fluid. In all cases, proteoglycan degrading activity of free neutrophil elastase was inhibited in a concentration dependent manner. In contrast, the inhibitory activities of $\alpha_{2} M G, \alpha_{1}$ PI, and SBTI were greatly impaired on cartilage bound neutrophil elastase, even at concentrations three- to 10-fold greater than those needed for total inhibition of the free enzyme. Furthermore, the data suggest that the bound enzyme would not be affected by further increases in inhibitor concentrations. Similarly, the pooled RA synovial fluid sample completely inhibited proteoglycan degradation by free enzyme at a 1 in 10 dilution, but only partially inhibited the degrading activity of cartilage bound neutrophil elastase, even when undiluted. The inhibitory activity of the low molecular mass inhibitor, $\mathrm{CMK}$, on bound neutrophil elastase was diminished but, unlike the high molecular mass inhibitors, CMK was able to inhibit the activity of bound enzyme completely at greater concentrations. The inhibitory activity of ONO-5046 was similar on both free and bound neutrophil elastase. The table shows $\mathrm{IC}_{50}$ values for each inhibitor on free and cartilage bound neutrophil elastase.

\section{Discussion}

This study shows that the activity of high molecular mass protease inhibitors, especially $\alpha_{2} M G$ and $\alpha_{1}$ PI, is greatly impaired when neutrophil elastase is bound to articular cartilage. In contrast, synthetic, low molecular mass protease inhibitors remain active. Considering that the maximum concentration of $\alpha_{2} M G$ used in this study $(10 \mu \mathrm{mol} / 1,7.25 \mathrm{mg} / \mathrm{ml})$ is in excess of its physiological concentration $(2-3 \mathrm{mg} / \mathrm{ml})^{15}$ and that the maximum concentration of $\alpha_{1}$ PI was 10 times greater than that required for total inhibition of the free enzyme, it is likely that the activity of these protease inhibitors against cartilage bound neutrophil elastase in pathological conditions will also be impaired. This idea is strengthened by the fact

$I C_{50}$ values of protease inhibitors on free and cartilage bound neutrophil elastase (NE)

\begin{tabular}{|c|c|c|c|c|c|c|}
\hline \multirow[t]{2}{*}{ Inhibitor } & \multirow{2}{*}{$\begin{array}{l}\text { Molecular mass } \\
(k D a)\end{array}$} & \multicolumn{2}{|l|}{ Free NE } & \multicolumn{2}{|c|}{ Cartilage bound $N E$} & \multirow[t]{2}{*}{$p \dagger$} \\
\hline & & $\begin{array}{l}I C_{50} \\
(\mu \mathrm{mol}))\end{array}$ & $\begin{array}{l}\text { Maximum } \\
\text { inhibition (\%) }\end{array}$ & $\begin{array}{l}I C_{50} \\
(\mu \mathrm{mol})\end{array}$ & $\begin{array}{l}\text { Maximum } \\
\text { inhibition (\%) }\end{array}$ & \\
\hline $\begin{array}{l}\alpha_{2} \text { MG } \\
\alpha_{1} \text { PI } \\
\text { SBTI } \\
\text { ONO-5046 } \\
\text { CMK }\end{array}$ & $\begin{array}{c}725 \\
52 \\
20 \\
0.5 \\
0.5\end{array}$ & $\begin{array}{l}1.69(0.09) \\
0.22(0.04) \\
1.77(0.09) \\
8 \cdot 13(1.10) \\
0.73(0.10)\end{array}$ & $\begin{array}{l}94 \cdot 5 \\
90 \cdot 0 \\
94 \cdot 5 \\
85 \cdot 7 \\
92 \cdot 0\end{array}$ & $\begin{array}{l}>10 \\
>3 \\
11.60(1.63) \\
11 \cdot 10(2 \cdot 76) \\
6.67(2.83)\end{array}$ & $\begin{array}{l}16 \cdot 7 \\
31 \cdot 1 \\
68 \cdot 8 \\
82 \cdot 7 \\
87 \cdot 4\end{array}$ & $\begin{array}{l}<0.001 \\
<0.001 \\
<0.01 \\
\text { NS } \\
<0.05\end{array}$ \\
\hline
\end{tabular}

Values are mean (SEM) of four separate experiments, $\alpha_{2} \mathrm{MG}=\alpha_{2}$ Macroglobulin; $\alpha_{1} \mathrm{PI}=\alpha_{1}$ protease inhibitor; SBTI $=$ soybean trypsin inhibitor; ONO-5046 = N-[2-[4-[2,2-dimethylpropionyloxy)phenylsulphonylamino]benzoyl] aminoacetic acid; CMK= N-methoxysuccinyl-Ala-Ala-Pro-Val-chloromethylketone. FFree $v$ bound enzyme (unpaired Student's $t$ test); NS = no significant difference. 
that human synovial fluid was unable completely to inhibit cartilage bound neutrophil elastase.

Cartilage bound neutrophil elastase was prepared by incubating cartilage with neutrophil elastase for 15 minutes at $0^{\circ} \mathrm{C}$. This allowed the rapid binding of neutrophil elastase to cartilage without any measurable proteolytic damage. Fifteen minutes incubation was sufficient to equilibrate neutrophil elastase binding to articular cartilage, as the degrading activity of the bound enzyme was shown to be identical to that of the free enzyme. This suggested an avid uptake of neutrophil elastase by cartilage which may in part be the result of ionic interactions between neutrophil elastase (cationic) and proteoglycan (polyanionic), engagement of the active site of the enzyme, or chondrocytes expressing high affinity receptors for neutrophil elastase. ${ }^{7}$ Proteoglycan degradation of cartilage sections was linear both for neutrophil elastase concentration and incubation time. Furthermore, the similar kinetics of proteoglycan degradation between free and cartilage bound neutrophil elastase suggested that the local concentration of neutrophil elastase was similar in both systems and allowed a direct comparison of the effects of protease inhibitors to be made.

The relative potency of protease inhibitors against proteoglycan degradation by cartilage bound neutrophil elastase was (from high to low): $\mathrm{CMK}>\mathrm{ONO}-5046>\mathrm{SBTI}>\alpha_{1} \mathrm{PI}>\alpha_{2} \mathrm{MG}$, and correlated with their increasing molecular masses. The limited effect of high molecular mass protease inhibitors on cartilage bound neutrophil elastase is similar to that reported with $\alpha_{1}$ PI, antileukoprotease $(11 \mathrm{kDa})$, eglin C $(8 \mathrm{kDa})$, and CMK on elastin bound neutrophil elastase. ${ }^{10}$

Synovial fluid showed a greater inhibition of cartilage bound neutrophil elastase than either $\alpha_{1}$ PI or $\alpha_{2}$ MG alone. Several explanations, including a possible additive effect of $\alpha_{1}$ PI and $\alpha_{2} M G$ can be suggested. However, lower molecular mass protease inhibitors such as antileukoprotease inhibitor $(11 \mathrm{kDa})$, which have been demonstrated in synovial fluid, ${ }^{16}$ are probably also contributing to the synovial fluid activity. We could not attribute the limited effect of high molecular mass protease inhibitors to pre-existing occupation of the active site of the enzyme by cartilage components, because ONO-5046 and CMK both bind the active site, and yet were able to inhibit totally the activity of cartilage bound neutrophil elastase. However, it has been shown that the diffusion of molecules into cartilage depends both on size and charge. ${ }^{17}$ Small cationic proteins such as neutrophil elastase are able to diffuse into cartilage, ${ }^{18}$ whereas high molecular mass anionic proteins such as $\alpha_{2} \mathrm{MG}, \alpha_{1} \mathrm{PI}$, and SBTI may be less able to do so. Low molecular mass protease inhibitors such as ONO-5046 and CMK may be less affected by these factors, and thus able to inhibit cartilage bound neutrophil elastase. However, none of these inhibitors did bind to cartilage, because preincubation of cartilage sections with inhibitors followed by a buffer wash left the cartilage equally vulnerable to degradation by elastase (data not shown).

The limited effect of protease inhibitors on cartilage bound neutrophil elastase is pathologically important. It suggests that, when neutrophil elastase has bound to articular cartilage, it is relatively resistant to the major endogenous inhibitors. The resulting proteoglycan degradation could facilitate degradation of other cartilage components such as type II collagen by metalloprotease ${ }^{19}$ and reactive oxygen species. ${ }^{1}$ Furthermore, cartilage bound neutrophil elastase can remain catalytically active for at least 24 hours (data not shown), which may provide an explanation for the observation that catalytically active neutrophil elastase can be localised at the cartilage-pannus junction of patients with RA. ${ }^{8}$

In summary, we suggest that the binding of neutrophil elastase to cartilage is one mechanism by which neutrophil elastase may remain active in the presence of endogenous high molecular mass inhibitors, but not synthetic low molecular mass inhibitors, which may have therapeutic potential.

We gratefully acknowledge the financial support of ONO Pharmaceutical Co Ltd, Japan, and the Arthritis and Rheumatism Council, Great Britain.

1 Burkhardt H, Schwingel M, Menninger H, Macartney H W, Tschesche $\mathrm{H}$. Oxygen radicals as effectors of cartilage destruction. Direct degradative effect on matrix components and indirect action via activation of latent collagenase from polymorphonuclear leukocytes. Arthritis Rheum 1986; 29: 379-87.

2 Havemann K, Gramse G. Physiology and pathology of neutral proteinases of human granulocytes. Adv Exp Med neutral proteinases of

3 Jensen H S, Christensen L D. Elastolytic activity of human blood monocytes characterised by a new monoclonal antibody against human leucocyte elastase. Relationship to rheumatoid arthritis. Clin Exp Rheumatol 1990; 8: 535-9.

4 Moore A R, Iwamura H, Larbre J P, Scott D L, Willoughby D A. Cartilage degradation by polymorphonuclear leukocytes: in vitro assessment of the pathogenic mechanisms. Ann Rheum Dis 1993; 52: 27-31.

5 Schalkwijk J, Van den berg W B, Van de Putte L B A Joosten L A B. Elastase secreted by activated polymorphonuclear leucocytes causes chondrocyte damage and matrix degradation in intact articular cartilage: escape from inactivation by alpha-1-proteinase inhibitor. $\mathrm{Br} f$ Exp Pathol 1987; 68: 81-8.

6 Weiss SJ. Tissue destruction by neutrophils. N Engl f Med 1989; 320: 365-76.

7 Bartholomew J, Lowther D A. Receptor mediated binding of leukocyte elastase by chondrocytes. Arthritis Rheum 1987; 30: 431-8.

8 Velvart M, Fehr K. Degradation in vivo of articular cartilage in rheumatoid arthritis and juvenile chronic arthritis by cathepsin G and elastase from polymorphonuclea leukocytes. Rheumatol Int 1987; 7: 195-202.

9 Bruch M, Bieth J G. Influence of elastin on the inhibition of leucocyte elastase by al-proteinase inhibitor and bronchial inhibitor. Biochem $\mathcal{f}$ 1986; 238: 269-73.

10 Morrison H M, Welgus H G, Stockley R A, Burnett D, Campbell E J. Inbibition of human leukocyte elastase bound to elastin: relative ineffectiveness and two mechanisms of inhibitory activity. Am $\Im$ Respir Cell Mol Biol 1990; 2: 263-9.

11 Stein R L, Trainor D A. Mechanism of inactivation of human leukocyte elastase by as chloromethyl ketone: kinetic and solvent isotype effect studies. Biochemistry 1986; 25: 541-9.

12 Kawabata K, Suzuki M, Sugitani M, Imaki K, Toda $M$, Miyamoto T. ONO-5046 a novel inhibitor of human neutrophil elastase. Biochem Biophys Res Commun 1991, 177: 814-20.

13 Arnett F C, Edworthy S M, Bloch D A, et al. The American Rheumatism Association 1987 revised criteria for the classification of rheumatoid arthritis. Arthritis Rheum $1987 ; 31: 315-24$

14 Nakajima K, Powers J C. Mapping the extended substrate binding site of cathepsin $\mathrm{G}$ and human leukocyte elastase. 7 Biol Chem 1979; 254: 4027-32.

15 Ekerot L, Ohlsson K. Interactions of granulocyte protease with inhibitors in rheumatoid arthritis. Adv Exp Med Biol 1984; 84: 335-44. 
16 Bohm B, Deutzmann R, Burkhardt H. Purification of a serine-protease inhibitor from human articular cartilage. Biochem f 1991; 274: 269-73.

17 Maroudas A. Distribution of molecules into articular cartilage. Biophys f 1970; 10: 365-79.

18 Janoff A. Granulocyte elastase; role in arthritis and in pulmonary emphysema. In: Havemann $\mathrm{K}$, Janoff $\mathrm{A}$, eds.
Neutrophil elastase of human polymorphonuclear leukocytes. Baltimore, Munich: Urban and Schwarzenberg, 1978.

19 Jasin H E, Taurog J D. Mechanisms of disruption of the articular cartilage surface in inflammation. Neutrophil elastase increases availability of collagen type II epitopes for binding with antibody on the surface of articular cartilage. $\mathcal{F}$ Clin Invest 1991; 87: 1531-6. 